\title{
HUBUNGAN INDEKS MASSA TUBUH DENGAN PENYAKIT JANTUNG KORONER DI RUMAH SAKIT UMUM CUT MEUTIA KABUPATEN ACEH UTARA
}

\author{
Mulyati Sri Rahayu* \\ Bagian Patologi Anatomi, Fakultas Kedokteran, Universitas Malikussaleh \\ Jl. Meunasah Uteunkot, Cunda- Lhokseumawe, Aceh

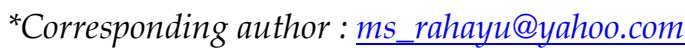

\begin{abstract}
Abstrak
Penyakit jantung koroner (PJK) merupakan penyakit kardiovaskular yang menyebabkan kematian nomor satu di Indonesia. Salah satu faktor risiko yang sering dijumpai pada penderita PJK adalah obesitas sentral. Lingkar leher dan lingkar pinggang saat ini dianggap sebagai salah satu cara pengukuran antropometri yang lebih sensitif, murah, dan mudah dalam menilai obesitas sentral. Penelitian ini bertujuan untuk mengetahui hubungan indeks massa tubuh dengan PJK di RSU Cut Meutia Kabupaten Aceh Utara tahun 2014. Penelitian ini menggunakan metode analitik dengan pendekatan cross sectional yang dilaksanakan pada bulan September 2014 sampai Januari 2015. Pengambilan sampel penelitian menggunakan cara convenient sampling dengan jumlah sampel yang memenuhi kriteria inklusi dan eksklusi sebanyak 56 orang. Analisis hubungan indeks massa tubuh dengan PJK menggunakan uji statistik Chi Square dengan derajat signifikan (a) 0,05. Berdasarkan hasil analisis bivariat tidak terdapat hubungan antara indeks massa tubuh dengan PJK $(p$ value $=0,197)$.
\end{abstract}

Kata kunci: Indeks Massa Tubuh; Penyakit Jantung Koroner 


\title{
RELATIONSHIP BETWEEN BODY MASS INDEX WITH THE INCIDENCE OF CORONARY HEART DISEASE IN CUT MEUTIA DISTRICT HOSPITAL
}

\begin{abstract}
Coronary heart disease (CHD) is cardiovascular disease that the first causes of death in Indonesia. One of the most risk factors that often found in patients with CHD is central obesity. Neck circumference and waist circumference are considered as the antrhropometric measurement which more sensitive, cheaper, and easier to assess central obesity. This study aims to determine the relationship between body mass index with the incidence of coronary heart disease in Cut Meutia district hospital in 2014. This study used analytic method with cross sectional design. This study was conducted in September 2014 until January 2015. Sampling studied used convenient sampling with 56 sampels that met inclusion and exclusion criteria. Analysis of the relationship between body mass index with the incidence of CHD uses statistic test of Chi Square with a significant degree (a) of 0,05 . Based on the results of the bivariate analysis there was not statistically relationship between body mass index with incidence of CHD ( $p$ value $=0,197)$.
\end{abstract}

Keywords: Body Mass Index; Coronary Heart Disease 


\section{Pendahuluan}

Penyakit jantung koroner (PJK) adalah gangguan fungsi jantung akibat otot jantung kekurangan darah karena adanya penyempitan pembuluh darah koroner. ${ }^{1}$ World Health Organization menyatakan 60\% dari seluruh penyebab kematian penyakit jantung adalah PJK. ${ }^{2}$ Laporan World Health Statistic tahun 2008 menyatakan terdapat 17,1 juta meninggal dunia akibat PJK dan diperkirakan meningkat menjadi 23,3 juta kematian di dunia pada tahun $2030 .^{3}$

Hasil Riset Kesehatan Dasar (Riskesdas) tahun 2007 menunjukkan PJK menempati peringkat ketiga penyebab kematian setelah stroke dan hipertensi dan prevalensinya terdapat $7,2 \%$ berdasarkan wawancara, sementara berdasarkan riwayat diagnosis tenaga kesehatan sebesar 0,9\%. Hasil Riskesdas tahun 2007 menunjukkan bahwa prevalensi PJK berdasarkan diagnosis dokter atau gejala di Provinsi Aceh sebesar 2\%. ${ }^{1}$

Faktor risiko PJK secara umum dibagi menjadi dua, yaitu faktor risiko yang tidak dapat dimodifikasi dan faktor risiko yang dapat dimodifikasi. Faktor risiko yang tidak dapat dimodifikasi adalah usia, jenis kelamin, dan genetik. Faktor risiko yang dapat dimodifikasi adalah hipertensi, hiperkolesterol, hipertrigliserida, diabetes melitus, merokok, obesitas, kurang aktivitas, dan stres. ${ }^{4}$

Jean Vaguen merupakan ilmuwan pertama yang mengemukakan adanya hubungan erat antara perbedaan morfologi tubuh atau tipe distribusi lemak tubuh dengan gangguan kesehatan yang berkaitan dengan faktor risiko obesitas. 5 Penumpukan lemak tubuh di bagian sentral tubuh akan meningkatkan risiko penyakit jantung dan pembuluh darah. ${ }^{6}$ Sel-sel lemak yang ada di dinding abdomen memiliki ukuran yang lebih besar yang didominasi oleh Low Density Lipoprotein (LDL) kolesterol yang membahayakan tubuh dan lebih siap melepaskan lemaknya ke dalam pembuluh darah dibandingkan dengan sel-sel lemak di tempat lain, sehingga risiko terbentuknya aterosklerosis pun meningkat. ${ }^{7}$

Obesitas adalah salah satu faktor risiko yang dapat dimodifikasi dan merupakan kunci penting dari terjadinya peningkatan kejadian PJK. ${ }^{8}$ Peningkatan berat badan secara signifikan dapat meningkatkan kejadian angina pectoris dan juga diprediksi timbulnya insidensi penyakit koroner dan gagal jantung kongestif (congestive heart failure). ${ }^{9}$ Penentukan tingkat obesitas dapat menggunakan pengukuran antropometri, salah satunya berupa pengukuran Indeks Massa Tubuh. ${ }^{10}$

Penelitian ini dilakukan dengan tujuan untuk mengetahui hubungan hubungan indeks massa tubuh dengan PJK di RSU Cut Meutia Kabupaten Aceh Utara tahun 2014.

\section{Metode \\ Rancangan Penelitian}

Jenis penelitian ini adalah penelitian analitik dengan pendekatan potong lintang (cross sectional study).

\section{Populasi dan Sampel}

Sampel penelitian ini adalah pasien PJK rawat jalan dan rawat inap yang datang ke RSU Cut Meutia Kabupaten Aceh Utara periode September 2014 sampai bulan Januari 2015 yang memenuhi kriteria inklusi dan eksklusi sebanyak 56 pasien.Teknik pengambilan sampelmenggunakan metode convenient sampling

\section{Prosedur}

Sumber data dalam penelitian ini diperoleh dari data primer berdasarkan hasil perhitunganIMT dengan mengukuran berat badan dan tinggi badan pasien.Data sekunderberupa jenis PJK diperoleh berdasarkan rekam medis pasien. 
Analisis

Analisis univariat untuk mendeskripsikan karakteristik pasien berupa usia, jenis kelamin, IMT dan penyakit jatung koroner.Hubungkan antara IMT dengan penyakit jantung koroner (PJK) menggunakan uji Chi-Square, jika dengan uji Chi-Square tidak memenuhi syarat, maka dipakai uji Fisher Exact.

\section{Hasil Penelitian}

Distribusi gambaran EKG

Hasil penelitian dari 56 pasien PJK di RSU Cut Meutia Kabupaten Aceh Utara bulan September 2014 sampai Januari 2015 didapatkan data distribusi frekuensi gambaran EKG seperti yang tertera pada tabel 1 .

Tabel 1. Distribusi frekuensi gambaran EKG pasien PJK RSU Cut Meutia Kabupaten Aceh Utara bulan September 2014 sampai bulan Januari 2015.

\begin{tabular}{ccc}
\hline Gambaran EKG & Frekuensi & Persentase (\%) \\
\hline APS & 35 & 62,5 \\
SKA & 21 & 37,5 \\
\hline Jumlah & 56 & 100
\end{tabular}

Sumber: Data primer, 2015

Tabel 1 menunjukkan bahwa pasien PJK di Rumah Sakit Umum Cut Meutia Kabupaten Aceh Utara paling banyak tergolong kategori APS (Angina Pektoris Stabil) yaitu sebanyak 35 orang (62,5\%) dibandingkan SKA yaitu sebanyak 21 orang $(37,5 \%)$.

Tabel 2. Distribusi frekuensi IMT pasien PJK RSU Cut Meutia Kabupaten Aceh Utara bulan September 2014 sampai bulanJanuari 2015.

\begin{tabular}{ccc}
\hline IMT & Frekuensi & Persentase (\%) \\
\hline Underweight & 8 & 14,3 \\
Normoweight & 34 & 60,7 \\
Overweight/Obesitas 1 & 14 & 25,0 \\
\hline Jumlah & 56 & 100 \\
\hline
\end{tabular}

Sumber: Data primer, 2015

Tabel 2 menunjukkan bahwa IMT pasien PJK di Rumah Sakit Umum Cut Meutia Kabupaten Aceh Utara bulan September 2014 sampai Januari 2015 paling banyak dengan normoweightyaitu 34 orang (60,7\%) dibandingkan yang Overweight/ Obesitas 1 sebanyak 14 orang (25\%) dan Underweightsebanyak 8 orang $(14,3 \%)$

\section{$\underline{\text { Distribusi IMT }}$}

Hasil penelitian dari 56 pasien PJK di RSU Cut Meutia Kabupaten Aceh Utara bulan September 2014 sampai Januari 2015 didapatkan data distribusi frekuensi IMT seperti yang tertera pada tabel 2. 
Tabel 3. Hubungan IMT dengan PJK

\begin{tabular}{|c|c|c|c|c|c|c|c|}
\hline \multirow{3}{*}{ IMT } & \multicolumn{4}{|c|}{ Gambaran EKG } & \multicolumn{2}{|c|}{ Jumlah } & \multirow{3}{*}{ p value } \\
\hline & \multicolumn{2}{|c|}{ APS } & \multicolumn{2}{|c|}{ SKA } & \multirow[b]{2}{*}{$\mathbf{n}$} & \multirow[b]{2}{*}{$\%$} & \\
\hline & $\mathbf{n}$ & $\%$ & $\mathbf{n}$ & $\%$ & & & \\
\hline Underweight & 5 & 62,5 & 3 & 37,5 & 8 & 100 & \multirow{4}{*}{0,197} \\
\hline Normoweight & 24 & 70,6 & 10 & 29,4 & 34 & 100 & \\
\hline Overweight/Obesitas 1 & 6 & 42,9 & 8 & 57,1 & 14 & 100 & \\
\hline Jumlah & 35 & 62,5 & 21 & 37,5 & 56 & 100 & \\
\hline
\end{tabular}

Sumber: Data primer, 2015

Hasil uji statistik Chi Square menunjukkan tidak terdapat hubungan antara IMT dengan PJK dengan $\mathrm{p}$ value 0,197 . Berdasarkan level signifikan 0,05 $p$ value lebih besar dari a $(0,197>0,05)$ yang berarti tidak terdapat hubungan antara IMT dengan kejadian PJK di RSU Cut Meutia Kabupaten Aceh Utara bulan September tahun 2014 sampai bulan Januari tahun 2015.

\section{Pembahasan}

Karakteristik pasien PJK berdasarkan umur didapatkan terbanyak pada periode usia 55-64 tahun.Hasil penelitian ini sesuai dengan teori yang dijelaskan oleh Sorrentino dalam Cholesterol reduction to prevent CHD (Coronary Heart Disease) bahwa risiko PJK terjadi pada pria yang berusia $\geq 55$ tahun, karena pada usia ini telah terjadi beberapa penurunan faal vaskular tubuh seperti tidak elastisnya lagi pembuluh darah dan kemampuan pemenuhan kebutuhan oksigen yang semakin berkurang. ${ }^{11}$ Usia membawa perubahan yang tidak terkendalikan pada tubuh manusia termasuk sistem kardiovaskular, seperti meningkatnya PJK. Perubahan-perubahan yang diakibatkan oleh usia juga dipengaruhi oleh masalah genetik serta diperberat oleh berkurangnya aktifitas fisik, dan berbagai penyakit degeneratif seperti diabetes melitus, hipertensi yang tidak terkendali, dan kebiasaan merokok. ${ }^{12}$

Berdasarkan jenis kelamin pasien PJK lebih banyak terdapat pada perempuan dibandingkan laki-laki, hal ini sejalan dengan penelitian yang dilakukan oleh Hariadi (2005) yang juga menemukan bahwa perempuan lebih banyak mengalami PJK dibandingkan laki-laki.Hasil penelitian ini mendapatkan bahwa banyak pasien PJK berjenis kelamin wanita karena pasien PJK yang dijadikan sampel dalam penelitian ini adalah wanita yang sudah mengalami menopause. ${ }^{13}$ Wanita yang sudah menopause berisiko PJK karena mengalami penurunan proteksi akibat penurunan jumlah hormon estrogen yang melindungi pada wanita selama masih aktif menstruasi, sehingga perbaikan jaringan vaskular menurun pada wanita yang telah masuk masa menopause, meningkatnya kadar LDL dan menurunnya kadar HDL, serta tahanan perifer yang semakin meningkat akibat berkurangnya elastisitas pembuluh darah pada lapisan tunika media. ${ }^{14}$

Berdasarkan pengukuran IMT dari 56 pasien PJK yang dijadikan sampel, terdapat pasien PJK banyak dengan normoweightyaitu 34 orang $(60,7 \%)$ dibandingkan yang Overweight/Obesitas 1 sebanyak 14 orang (25\%) dan Underweight sebanyak 8 orang $(14,3 \%)$. Besar nilai IMT seseorang dapat menjadi risiko mereka untuk terkena penyakit jantung, terutama pada orangorang dalam kategori obesitas. Pada orangorang dengan obesitas ini, kerja jantungnya lebih besar apabila dibandingkan dengan orang-orang non-obes dan dapat menyebabkan hipertrofi dari organ ini seiring dengan penambahan berat badan. Cardiac output, stroke volume (volume 
sekuncup) dan volume darah intravaskuler juga akan mengalami peningkatan. ${ }^{15}$

Hasil penelitian ini menyatakan bahwa pasien PJK yang memilki gambaran EKG APS sebanyak 35 orang dan yang memiliki gambaran EKG SKA sebanyak 21 orang. Hal ini sesuai dengan penelitian yang dilakukan oleh Jian dan Hongliang (2012) juga menyatakan hal yang sama yaitu pasien PJK yang memiliki gambaran EKG APS lebih banyak dibandingkan pada pasien PJK dengan gambaran EKG SKA, yaitu 2:1.16 Perbedaan jumlah sampel yang ditemukan oleh peneliti terjadi karena kebanyakan pasien SKA yang berobat ke RSU Cut Meutia Kabupaten Aceh Utara langsung dirujuk ke RS Zainal Abidin Kota Banda Aceh untuk dilakukan pemeriksaan biokimia darah dan angiografi, serta untuk diberi terapi lebih lanjut, sehingga pasienpasien SKA tersebut belum sempat dijadikan sampel oleh peneliti. Peneliti juga menemukan bahwa pasien PJK dengan gambaran EKG SKA cukup banyak diderita oleh laki-laki dan juga banyak pasien PJK laki-laki yang sudah mengalami komplikasi menjadi CHF (Congestive Heart Failure).Hal ini menunjukkan bahwa pasien laki-laki cenderung memiliki manifestasi PJK yang lebih berat dibandingkan wanita.

Berdasarkan analisis bivariat dilakukan crosstabs antara IMT dengan gambaran EKG pasien PJK, diperoleh APS dengan overweight/obesitas sebanyak 6 orang, pasien SKA dengan overweight/obesitas sebanyak 8 orang. Hal ini membuktikan bahwa overweight/ obesitas lebih banyak terdapat pada pasien SKA dibandingkan dengan pasien APS. Hal ini sejalan dengan hasil penelitian yang diperoleh oleh Orangorang yang menderita PJK juga memiliki nilai IMT lebih tinggi daripada orang-orang yang tidak menderita PJK. ${ }^{17}$ Prentice (2001) melaporkan bahwa risiko PJK terendah dimiliki oleh orang- orang dengan IMT sebesar $23 \mathrm{~kg} / \mathrm{m} 2$ dan masing - masing peningkatan nilai IMT satu angka dapat berisiko mortalitas PJK sebesar $2 \% .^{18}$

Uji Chi Square didapatkan nilai p value sebesar 0,197 yang berarti nilai $\mathrm{p}$ value $>\mathrm{a}$ $(0,05)$ hal ini menunjukkan bahwa tidak terdapat hubungan IMT dengan kejadian PJK. Hasil penelitian Wiyono dkk. (2004) menunjukkan bahwa terdapat hubungan antara rasio lingkar pinggang-pinggul dengan kadar kolesterol (total, LDL dan HDL) pada orang dewasa di Kota Surakarta. Penelitian tersebut menyebutkan bahwa Indeks Massa Tubuh (IMT) sebagai alat ukur antropometri yang lebih populer dimasyarakat dianggap kurang peka terhadap tingginyadeposit lemak tubuh pada orang dewasa yang seringberkorelasi dengan kejadian PJK.19 Sekalipun Poirer (2008) menyatakan bahwa hubungan yang kuat antaraindeks massa tubuh dengan kejadian PJK terutamadi antara populasi laki-laki. ${ }^{20}$ Massa tubuh terdiri dari berat lemak/fat mass dan berat lemak bebas/fat freemass yang terdiri dari tulang, otot dan cairan. Dengan demikian tingginya nilai IMT tidak selalu karena lemak, tetapi dapat disebabkan karena otot seperti pada seorang binaragawan atau atlet. Jumlah otot yang tinggi dapat menghasilkan nilai IMT yang tinggi juga sehingga IMT dapat menyebabkan misklasifikasi untuk menghitung jumlah lemak tubuh. Pada penelitian lain disebutkan bahwa IMT kurang spesifik dalam menilai obesitas. ${ }^{2}$

\section{Kesimpulan}

Penelitian ini menunjukkan bahwa tidak terdapat hubungan yang bermakna antara indek massa tubuh dengan kejadian penyakit jantung koroner. Oleh karena itu diperlukan metode antropometri lain dalam mengidentifikasi obesitas sebagai screening penyakit kardiovaskular. Namun demikian bagi pasien dengan kategori overweight dan obesitas harus dilakukan intervensi untuk target berat badan ideal berdasarkan IMT 
$<25 \mathrm{~kg} / \mathrm{m}^{2}$ guna menurunkan risiko penyakit metabolik.

\section{DAFTAR PUSTAKA}

1. Kementerian Kesehatan RI. Angka penyakit jantung koronerdi Indonesia dan di Aceh. Profil Kesehatan Indonesia 2011, 2012: 97-98.

2. Supriyono M. Faktor-faktor risiko yang berpengaruh terhadap kejadian penyakit jantung koroner pada kelompok usia $\leq 45$ tahun di RSUP Kariadi dan RSU Telogorejo Semarang tahun 2008 [Tesis]. Semarang: Universitas Diponegoro, 2008.

3. WHO. Cardiovascular disease 2013. [cited 2014 Mei 20]. Available from: URL: http://www.who.int/ topics/ obesity/en.

4. Departemen Kesehatan RI. Pedoman pengendalian penyakit jantung dan pembuluh darah 2007: 8-14.

5. Liubov BN, Sohar E, Laor A. Neck circumference as $\mathrm{s}$ simple screening measure for identifying overweight and obese Patients. The North Association for The Study of Obesity 2012; 9(8): 47077.

6. Departemen Kesehatan RI. Pedoman pengendalian penyakit jantung dan pembuluh darah; Keputusan Menteri Kesehatan Indonesia No. 854/Menkes/SK/IX/2009, 2009.

7. Ayudhia M. Hubungan antar obesitas dengan tipe penyakit jantung koroner di poliklinik jantung Rumah Sakit Umum Daerah Cengkareng pada bulan Januari-Desember 2010 [Skripsi]. Yogyakarta: Fakultas Kedokteran Universitas Pembangunan Nasional, 2012.

8. Proverawati A. Obesitas dan gangguan perilaku makan pada remaja. Yogyakarta: Nuha Medika, 2010:71-72.

9. Ashton WD, Nanchahal K, Wood DA. Body mass index and metabolic risk factor for coronary heart disease in woman. European Heart J 2001; 22:4655.

10. Leupker RV, Evans A, McKeigue P, Reddy KS. Cardiovascular Survey Methods. Ed.3. Geneva: WHO, 2004

11. Yuliani F, Oenzil F, Iryani, D. Hubungan berbagai faktor risiko terhadap kejadian penyakit jantung koroner pada penderita diabetes mellitus tipe 2. Jurnal Kesehatan Andalas 2014; 3(1): 39-42.

12. Andarmoyo S, Nurhayati T. Laki-laki dan riwayat keluarga dengan penyakit jantung koroner berisiko terhadap penyakit jantung koroner [Artikel Penelitian]. Ponorogo: Fakultas Ilmu Kesehatan Universitas Muhammadiyah, 2013.

13. Hariadi, Ali AR. Hubungan obesitas dengan beberapa faktor risiko penyakit jantung koroner di laboratorium klinik Prodia Makassar tahun 2005 [Artikel Penelitian]. Makassar: Prodia, 2005.

14. Rahajoe AU. Penyakit jantung pada perempuan. Jurnal Kardiologi Indonesia 2007; 28(3):169-71.

15. Supariasa IDN, Bakri B, Fajar, I. Penilaian status gizi. Jakarta : EGC, 2002:56-62.

16. Jian L, Hongliang C. The study of corellation between distribution of body fat and coronary heart disease. Heart 2012; 2(98):161-65.

17. Fava SL, Wilson PWF, Schaefer FJ. Impact of body mass index on coronary heart disease risk factors in men and women. Am Heart Ass 1996;16:1509-15.

18. Prentice AM, Jebb SA. Beyond Body Mass Index. J Obes Rev 2001;2(3):141-47.

19. Wiyono S, Bantas K, Hatma RD. Hubungan antara rasio pinggangpinggul dengan kadar kolesterol pada orang dewasa di kota surakarta (analisis data riset unggulan terpadu 1996). Cermin Dunia Kedokteran 2004;143: 4549. 
20. Poirier P. Healthy lifestyle even if you are doing everything roght, extra weight carries an excess risk acute coronary events. Circulation: Journal of the American Heart Association 2008; 117: 3057-59. 